\title{
A PÓS-GRADUAÇÃO DA USP: FONTE DE CONHECIMENTO E DE FORMAÇÃO DE PROFISSIONAIS ALTAMENTE QUALIFICADOS
}

\author{
Antonio Carlos Hernandes ${ }^{1}$
}

A pós-graduação no Brasil, como a conhecemos nos dias de hoje, teve como início de sua estruturação o parecer n. 977 CES/CFE, de 3 de dezembro de 1965, conhecido como parecer Newton Sucupira. Passados mais de 55 anos, esse documento oficial continua sendo uma referência sistemática da pós-graduação em nosso país.

A Capes (Coordenação de Aperfeiçoamento de Pessoal de Nível Superior) e o CNPq (Conselho Nacional de Desenvolvimento Científico e Tecnológico), duas das principais agências de fomento do país, somadas à Fapesp (Fundação de Amparo à Pesquisa do Estado de São Paulo), têm aportado recursos financeiros de maneira a garantir a formação de profissionais qualificados, com títulos de mestre e doutor, nas mais diferentes áreas do conhecimento, e contribuído primordialmente para a consolidação do sistema nacional de pós-graduação. Essas instituições seguem acompanhando e coordenando o avanço e a capilaridade dos cursos de pós-graduação no território nacional à luz do Plano Nacional de Pós-Graduação (PNPG 2011-2020).

A Universidade de São Paulo, desde a sua criação, pelo Decreto n. 6.283, de 25 de janeiro de 1934, tem como missão "promover, pela pesquisa, o progresso da ciência" e, ao mesmo tempo, "transmitir, pelo ensino, conhecimentos que enriqueçam ou desenvolvam o espírito, ou sejam úteis à vida”. Sempre atenta à sua missão, a USP ao longo das décadas tornou-se o maior e o principal centro de formação de pós-graduação stricto sensu do Brasil. Como consequência direta de seu engajamento, a universidade hoje é responsável por mais de $20 \%$ de toda a produção científica qualificada do país, com capacidade instalada de laboratórios de pesquisa de alta complexidade e número expressivo de pesquisadores.

Naturalmente, a formação de profissionais diferenciados foi e ainda é decisiva para o avanço do país nas mais diversas áreas. Para a redução de desigualdades regionais, a descentralização do ensino de pós-graduação, com a formação de mestres e doutores atuando em todos os Estados da federação, tem uma forte e importante contribuição da USP. Muito do progresso que o Brasil experimentou com a expansão do ensino superior deveu-se à capacidade da Universidade de São Paulo de prover doutores qualificados em número suficiente para que se pudesse implantar novas instituições de ensino no país.

\footnotetext{
1 Vice-Reitor da Universidade de São Paulo.
} 
O papel da USP no Sistema Nacional de Pós-Graduação é expressivo, seja ao longo da história, seja no momento presente. O número de programas de pósgraduação stricto sensu surpreende por sua abrangência, marcada por um grau elevado de internacionalização em uma diversidade de áreas do conhecimento. Entre 2004 e 2019, o número de programas de pós-graduação cresceu 73\%, ou seja, foi de 153 para 264 programas, dos quais $92 \%$ foram avaliados com notas entre 4 e 7 pela Capes, segundo o Anuário Estatístico da Universidade. No mesmo período, as áreas de concentração cresceram 56\%, totalizando 851 em 2019.

Nesse mesmo período de 2004 a 2019, o número de pós-graduandos regularmente matriculados na USP cresceu somente $20 \%$, excetuando os alunos com matrícula especial. Em 2019, a USP contava com 14.047 mestrandos e 15.248 doutorandos. A restrição de recursos financeiros tornou-se um limitador do potencial de crescimento que a universidade detém. A tímida expansão do financiamento de bolsas e de recursos de custeio e capital para a pesquisa por parte do Estado brasileiro trouxe sérios prejuízos para todo o sistema de pós-graduação do país, e isso é muito mais perceptível nas áreas em que se exige modernização contínua de equipamentos e protocolos necessários para se estar na fronteira do conhecimento e da inovação.

Se, por um lado, a taxa de crescimento do número de jovens que optaram por cursar a pós-graduação cresceu timidamente em relação aos anos anteriores à 2004, por outro, o número de titulados cresceu 36\% entre 2004 e 2019. Destaca-se o crescimento do número de doutores formados: de 2.117 em 2004 para 2.862 em 2019. São quase 3 mil pesquisadores com formação altamente qualificada, em todas as áreas, e que podem contribuir decisivamente para o progresso do conhecimento e para o avanço científico, cultural e social do país.

Todavia, é preciso lembrar que a formação de pesquisadores altamente qualificados demanda tempo (de 10 a 15 anos) e recursos financeiros. São necessárias políticas consistentes e estáveis para obter avanços, reduzir as desigualdades e enfrentar os grandes desafios da sociedade.

Desde 2020, estamos experimentando em todo o mundo a pior calamidade de saúde pública dos tempos recentes. A chegada da Covid-19 trouxe muita dor e tristeza a um grande número de famílias, alterou o cotidiano de todos e aprofundou os problemas oriundos da desigualdade social. Ao mesmo tempo, a crise atual tornou evidente que países com forte sistema de pesquisa, formação de recursos humanos e inovação respondem mais prontamente com soluções para mitigar os efeitos perversos da pandemia.

A vacina obtida em tempo recorde é o resultado direto de políticas científicas consistentes e de longo prazo empreendidas por governos dos países líderes. No Brasil, o FNDCT (Fundo Nacional de Desenvolvimento Científico e Tecnológico), criado em 1969 para ser o instrumento de integração da ciência e da tecnologia com o desenvolvimento 
nacional, sofre (e sofreu) com a irregularidade e o contínuo contingenciamento no aporte de recursos financeiros para sua operacionalização.

Não se constrói uma nação independente sem um sistema nacional de ciência e tecnologia robusto e prioritário. Não se avança sem a formação de recursos humanos capazes de ser agentes transformadores da sociedade. Portanto, o país precisa mudar. É necessário um projeto de Estado para reverter o grave quadro da ciência e da tecnologia do país.

É em um cenário adverso que a grandeza de uma instituição se torna mais evidente. A USP ocupou lugar de destaque durante a pandemia: com apoio decisivo ao país em suas diversas áreas; como fonte segura e confiável de informação e de conhecimento para o desenvolvimento nacional; e, mesmo com as adversidades, não deixou de formar profissionais altamente qualificados. Assim, firme em sua missão, a USP contribui com a formação pós-graduada de recursos humanos para o Brasil, e segue à disposição para continuar cooperando com a elaboração do Plano Nacional de PósGraduação (2021-2030). 